Revista Aspas

ppgac - USP

Artigo

\title{
AS INTERVENÇÕES ARTÍSTICAS: AS POSSÍVEIS FRESTAS DAS RUAS
}

THE ARTISTIC INTERVENTIONS: THE POSSIBLE CRACKS IN THE STREETS INTERVENCIONES ARTÍSTICAS: LAS POSIBLES CRUCES DE LAS CALLES

Marcelo Eduardo Rocco de Gasperi

Marcelo Eduardo Rocco de Gasperi UFOP; Professor Adjunto. Artes Cênicas. Doutor em Artes. E-mail: Marcelorocco1@gmail.com 


\section{Resumo}

O presente texto pretende contribuir conceitualmente para os estudos acerca das intervenções urbanas, vistas como propostas de enfrentamento às demarcações territoriais excludentes. As noções de interferências artísticas são discutidas aqui como fontes problematizadoras que se contrapõem aos discursos hegemônicos. Tais discursos organizam a cidade evidenciando os diferentes espaços urbanos, rotulados de acordo com propósitos distintos. Neste contexto, pode-se dizer que as intervenções urbanas agem sobre um cenário prévio da cidade, criando outras formas de se ver a paisagem urbana e de interagir com a mesma, traçando novos desenhos.

Palavras-chave: corpos, discursos hegemônicos, espaço público, enfrentamento, intervenções urbanas

\section{Abstract}

This text intends to contribute conceptually to the studies about the urban interventions as proposals to confront the territorial demarcations excluding. The notions of artistic interference are discussed here as problematizing sources that oppose the hegemonic discourses. Such discourses organize the city in such a way that it becomes possible to perceive the different urban spaces, labeled according to different purposes. In this context, it can be said that urban interventions act on a previous landscape of the city, creating other ways of seeing the urban landscape and interacting with it, drawing new designs.

Keywords: bodies, hegemonic discourses, public place, confrontation, urban interventions.

\section{Resumen}

Este texto pretende contribuir conceptualmente a los estudios sobre intervenciones urbanas como propuestas para enfrentar las demarcaciones territoriales excluyentes. Las nociones de interferencia artística se discuten aquí como fuentes problemáticas que se oponen a los discursos hegemónicos. Tales discursos organizan la ciudad de tal manera que se hace posible percibir los diferentes espacios urbanos, etiquetados de acuerdo con diferentes propósitos. En este contexto, se puede decir que las intervenciones urbanas actúan sobre un paisaje anterior de la ciudad, creando otras formas de ver el paisaje urbano e interactuar con él, dibujando nuevos diseños.

Palabras clave: cuerpos, discursos hegemónicos, espacio publico, afrontamiento, intervenciones urbanas 


\section{Os enunciados hegemônicos: demarcar espaços, marcar corpos.}

As cidades atuais possuem territórios marcados pela diferença. Diversas regiões das cidades carregam traços peculiares que designam imagens simbólicas acerca de seus espaços, locais de ostentação de poder, pontos que representam o imaginário urbano sobre as diferentes classes sociais. Recintos consagrados como patrimônios das cidades, locais que demarcam a divisão social a partir de uma ideia homogeneizada do que vem a ser o urbano. A supervalorização de determinados espaços em prejuízo de outros faz parte do contraste da vida cotidiana nas cidades. A determinação dos valores simbólicos e financeiros acerca de alguns espaços é proveniente de vários fatores, dentre eles, a gentrificação, a especulação imobiliária, o desejo de enobrecimento de certos bairros, o valor de uso e de frequência de pessoas em determinados espaços, entre muitos outros.

Bauman (2007) acredita que na história da democracia ocidental os direitos políticos são, em parte, sinônimos de privilégios das classes sociais mais elevadas, dando a essas classes maiores acessos. Essa noção parte do pressuposto de que tais direitos são embasados na quantidade de recursos materiais e financeiros que essas classes sociais possuem. As pessoas consideradas inadequadas para frequentar determinados espaços são alvo do monitoramento constante, devendo permanecer: "[...] longe da comunidade dos sujeitos cumpridores da lei" (BAUMAN, 2007, p. 76). Aprimorando o pensamento acima, pode-se dizer que as áreas mais habitáveis de uma cidade são as que, sob algum aspecto, afastaram de seu entorno os sujeitos de classes sociais mais baixas. Sendo assim, parte do pensamento hegemônico se pauta na luta contra a insegurança na cidade, a fim de valorizar ordenadamente os ambientes urbanos.

Ao serem fortificados, os espaços passam a ser usados como uma espécie de refúgio para os "sujeitos de direitos", conferindo-lhes um aspecto mais homogêneo na cidade, em que o "diferente" fica do lado de fora dos ambientes, ou seja, não incomoda. Esta forma de privatização dos espaços confere mudanças dramáticas aos imaginários urbanos, refletindo 
diretamente nos valores dos sujeitos. Ela abre grandes fossos sociais. Neste caminho, pode-se dizer que as cidades atuais possuem espaços que são classificados de acordo com as diferentes relações entre os seres, resultando em discursos articulados a partir da circulação intensa de pessoas, de veículos e até de produtos mercadológicos, entre outros elementos constituintes da sociedade contemporânea. Dentro da esfera social há espaços definidos como lugares nobres, outros como ambientes marginais ou de risco. Há também ambientes ditos comumente como seguros ou como inseguros, criando lugares divididos por classes sociais, que vão desde shoppings centers até comunidades periféricas.

Essa percepção sobre as formas de utilização dos espaços na cidade gera uma tomada de consciência em parte dos sujeitos, buscando superar as contradições que o sistema capitalista causa. Isto pode fazer com que diferentes sujeitos transitem em distintos lugares da cidade, tendo ideologias contrárias às concepções prévias de uso dos espaços. Os discursos da cidade - que, muitas vezes, aparecem em oposição aos sistemas de poder - tendem a colidir, a enfrentar as hierarquizações dos espaços urbanos, podendo gerar ações que envolvam uma tomada de decisões políticas (BECK, 1995). A cidade passa a ser vista, então, como um lugar de lutas, de conflitos e de reconfiguração de pensamentos. Nesta ótica, a cidade passa a ser palco de experiências políticas de modificação estrutural, abrindo frestas no cotidiano. As formas de resistência fazem com que os sujeitos mudem aspectos sociais dados, anteriormente, como estáticos (LEITE, 2007). Mediante a tais perspectivas, pode-se afirmar que os espaços públicos da cidade, tais como a rua, são locais privilegiados para o confronto e para o compartilhamento de discursos, podendo ameaçar diretamente o poder do capital.

Quando os organismos políticos hegemônicos agem sobre o cidadão a partir de verdades irrevogáveis tentam retirar dele a possibilidade de mudança. Isto gera a errônea ideia de livre-arbítrio em função de uma falsa liberdade de escolha, pois a seleção de produtos, de bens materiais e imateriais já foi feita anteriormente à sua vontade. Consequentemente, a mudança passa a ser, muitas vezes, indesejada, pois se torna sinônimo de problema, contrariando a harmonia supostamente dada pelo modismo social. 
A totalidade do pensamento faz-se necessária para que formas de pensamento homogeneizado se perpetuem, diminuindo a capacidade crítica dos sujeitos que deveriam buscar por princípios da verdadeira autonomia. $\bigcirc$ reforço constante do pensamento hegemônico é visto pelas elites como um elemento necessário. Não é reiterado apenas para que os sujeitos permaneçam indiferentes uns aos outros, às mazelas e às tragédias sociais, mas para que os mesmos contribuam voluntariamente para as práticas de segregação social, de tanto assimilarem os discursos anteriormente produzidos. Uma aparente livre escolha que, na verdade, fora amplamente estimulada no percurso de vida dos sujeitos.

Bauman (2007) retrata a forma rotineira de contenção do movimento dos corpos que prima pela "harmonia" em grupo, no sentido amplo do termo, em contraposição à desordem. Tais preocupações corroboram diretamente para o desmantelamento de ações individuais e coletivas que possam impedir a circulação imediata do capital, das privatizações dos espaços públicos, da negação do projeto neoliberal existente, enraizado na cultura economicista. Nessa busca pela ordem, o poder é legitimado todos os dias, na tentativa de diminuição do pensamento criador, inovador, na falsa consonância com os desejos da sociedade. Desse modo, as experiências coletivizadas que não passam pela lógica do capital, não são bem digeridas pela sociedade de controle. Em linhas gerais, os discursos hegemônicos requerem os espaços públicos como redutos da mercadoria, da passagem, do trabalho, do turismo, entre outros aspectos secundários. Logo, quando o cidadão se insere melhor nas ideologias hegemônicas, seu engajamento político pode se reduzir.

Diante das problemáticas apontadas, pode-se perguntar, então, "Quais os mecanismos de ação dos sujeitos pela busca da autonomia, mediante a padronização dos espaços?". Perante a questão, pode-se dizer que há sujeitos, redes, e grupos contemporâneos que passam a enxergar as ruas e os espaços públicos como locais de confronto estético, político e ideológico. 


\section{As intervenções artísticas na cidade: confrontar o conforto}

Em meio à crise das experiências compartilhadas, diversos sujeitos subvertem as relações aparentemente enrijecidas entre espaços públicos e mercado. Relações que colocam o cidadão como mero consumidor pagante, fazendo com que diversas pessoas tomem atitudes que busquem extrapolar algumas noções usuais da cidade. A tentativa de controle de utilização dos espaços públicos entra em constante colisão com os anseios dos sujeitos que visam escapar, apropriar e desmembrar ordens prévias do sistema hierárquico, gerando tensões simultâneas, disputas e manifestações que desafiam certas preleções estratificadas de poder. Tal inconformismo perante a institucionalização do uso da rua e de demais espaços públicos, que visa definir quem e quando usar tais locais, ascende em parte dos sujeitos a pretensão de se preencher tais espaços com ações alheias ao ritmo usual da cidade. A partir de diversas formas de ocupação - e mantendo a liberdade de uso da rua como ideário político - muitos grupos sociais se movimentam em oposição ao pensamento dominante, criando alternativas para se vivenciar a cidade.

Utilizando as ruas como um espaço político, pode-se dizer que parte dos sujeitos almeja a percepção de áreas da cidade além da espetacularização da vida, criando novas possibilidades de discursos mediante aos fatos apresentados. A rua como um território vivo dentro do eixo urbano, repleta de tensões e de vontades por parte dos sujeitos que passam por ela, pode ter, em sua tessitura, diferentes formas de utilização e de compreensão de seu uso contínuo. Como eixo de passagem dos transeuntes, a rua e os espaços públicos podem ser vistos também como passarelas de identidades, de reflexão e de energias compartilhadas, testemunhando diferentes formas de vida.

Em meio às diversas possibilidades de ações, de intervenções dos sujeitos na cidade, há diferentes formas de atuação artística sobre os eixos urbanos, tais como as intervenções urbanas. Elas promovem provocações acerca das noções sedimentadas da cidade, gerando visões diversificadas 
sobre a feitura de arte a partir de estéticas distintas. Dentre a vasta conceituação acerca das intervenções urbanas, pode-se considerá-las como manifestações que intervêm, sob algum aspecto, em um cenário urbano preexistente, cuja função habitual de uso passa a ser interrogada, abrindo novas percepções relacionais aos sujeitos.

Segundo Mesquita (2008), as intervenções urbanas possuem o compromisso de inserção estética em diferentes arquiteturas da cidade, oferecendo maior horizontalidade nas construções artísticas em vias públicas. As intervenções urbanas possuem um caráter dinâmico de apresentação, o que dá a elas uma espécie de livre circulação pelo tecido urbano, na busca de maior autonomia criativa, distinguindo-as assim, das ações artísticas mais institucionalizadas. Geralmente, as intervenções urbanas são marcadas pelo caráter político de atuação, enfatizando as discussões atuais da sociedade através de ações em tempos limitados, efêmeros, em um aspecto de estreitamento entre a feitura e os habitantes das cidades. É nesse viés que as intervenções urbanas atuam como micropolíticas foucaultianas em lugares específicos, habitando o cotidiano a partir de pequenas e novas molduras na cidade.

Grosso modo, as intervenções urbanas nascem de diferentes interferências dos indivíduos sobre a cidade. São ações artísticas que se constroem sobre a paisagem urbana. Entre os distintos feitos, compreendidos genericamente como formas de intervenções urbanas, entende-se as noções de intervenção sobre o aspecto de ações artísticas efêmeras e processuais, realizadas nas ruas e em demais espaços públicos.

Neste contexto, pode-se dizer que as intervenções urbanas agem sobre uma paisagem prévia da cidade. Ou seja, diante de uma arquitetura/de um lugar preexistente, as intervenções criam outras formas de se ver a paisagem urbana e/ou de interagir sobre ela, traçando novos perfis, novos desenhos, novos desvios na cidade, mesmo que esses perfis/desenhos/desvios sejam efêmeros. Consequentemente, a experiência da rotina do cotidiano dá passagem a uma experiência "extraordinária", pois tal experiência desestrutura momentaneamente o olhar prévio dos sujeitos que observam e/ou atravessam as intervenções, possibilitando criar outros 
pontos de vista aos transeuntes, além de permitir novos e pequenos mapeamentos dos espaços públicos. Assim, alguns olhares aparentemente opacos, viciados, rotineiros sobre as paisagens urbanas dão lugar a novos repertórios, a outras atribuições nos significados de uso, de contemplação e de experiência na cidade. Ao intervir no espaço público, o artista promove questionamentos, devaneios, interesses, desinteresses, análises, afetos e desafetos nos sujeitos que compartilham a experiência estética no âmbito urbano.

Em geral, as intervenções urbanas são heterogêneas, processuais e abertas a múltiplos entendimentos, bagunçando uma suposta ordem do cotidiano. Sendo assim, elas propõem deslocamentos nos olhares dos passantes, lançando provocações e, talvez, incertezas sobre o que está por vir. As intervenções urbanas "arremessam" para os passantes os elementos constitutivos de suas ações, cabendo a cada transeunte a decisão acerca da forma (ou das formas) de se continuar o jogo proposto: ora observando, ora ignorando, ora se aproximando, ora se afastando, etc. Ao optar por dar continuidade ao jogo, fazendo parte dele, o passante auxilia na reconfiguração momentânea da paisagem urbana. As intervenções urbanas podem causar diferentes perspectivas e até possíveis atritos contra alguma ordem instaurada como, por exemplo, quando uma intervenção se dá em meio ao fluxo de carros, forçando a interrupção súbita do tráfego, no sistema viário urbano.

Dentro desta discussão inicial, pode-se dizer que as intervenções urbanas se situam no âmbito funcional do dia a dia, procurando trazer ressignificações simbólicas que escapem (um pouco) do hábito. Neste enfoque, as intervenções urbanas se apresentam em meio aos elementos constitutivos do cotidiano. Elas podem se alimentar de tais elementos objetivando modificar, sob algum aspecto, o contorno habitual do ambiente urbano. Através de uma investigação artística qualquer, as intervenções urbanas propõem modos diferenciados de leitura sobre a cidade. As diferentes características dos espaços públicos delineiam a diversidade das intervenções urbanas, pois os espaços podem aparecer como suportes para as feituras, como motes para as ações e, até, como obstáculos para as 
mesmas. Alargando mais este assunto, pode-se dizer que os artistas que realizam as intervenções urbanas carregam, muitas vezes, algumas informações dos locais específicos sobre os quais irão trabalhar, dialogando com os mesmos e/ou até enfrentando algumas situações que se apresentam nos espaços.

Além disso, muitos artistas que interveem sobre os espaços públicos com finalidades plásticas e reflexivas podem colocar uma lente de aumento sobre alguns aspectos da vida social, objetivando produzir sensações diferenciadas aos passantes. Sensações que possam caminhar ao encontro de novas percepções acerca de regulamentos de uso da cidade, institucionalizados por meio de leis, pelo hábito, pela tradição. Para alguns artistas, as intervenções urbanas se apresentam como um campo de linguagens dinâmicas, polissêmicas, constituídas por diferentes procedimentos estéticos que dão visibilidade aos diversos assuntos de caráter político-social: "A intervenção urbana teria muito mais a ver com a apreensão de uma falha, de uma ausência ou de uma percepção do contexto da vida urbana que demandasse, então, a ação do artista ou coletivo de artistas" (Garrocho, 2015, p. 153).

A arquitetura da cidade que, algumas vezes, aparece como um lugar pronto, acabado, passa a receber novas camadas de leituras em sua superfície, propiciando novas fugas às cristalizações do olhar sobre a mesma. Mesquita (2008) acredita que as intervenções urbanas propiciam um valor diferenciado de uso às relações na cidade. $O$ valor simbólico de uma intervenção urbana ultrapassa as relações de consumo propiciadas pela sociedade do capital, enfatizando o afeto, a troca e a experiência entre os sujeitos. Em geral, as intervenções urbanas exigem uma corporeidade imediata proporcionando - aos passantes - opções que extrapolam os caminhos de contemplação que uma obra artística possui. Ou seja, dentro da ideia de intervenção em espaços públicos, os transeuntes podem observar as ações - como fariam com quaisquer outras ações artísticas - mas podem também, possivelmente, experimentar a proximidade com as feituras. Por vezes, podem tatear, estreitar, criando relações sinestésicas com a experiência que, muitas vezes, se mescla com o cotidiano. 
Geralmente, as intervenções exploram uma dinâmica em que a cidade aparece como um elemento centralizador da feitura artística, na possibilidade de um diálogo direto com os passantes. Nesta perspectiva, algumas intervenções urbanas de cunho artístico objetivam criar materiais provocativos, sem o intuito imediato de fecharem as possíveis leituras sobre as obras: "Ações de intervenção e composição urbanas, de alguma forma, criam zonas temporárias e espaciais renovadas pela presença do corpo, afirmando a cidade como espaço de contaminação e heterogeneidades" (Gasperi et al., 2015, p. 6). Elas deixam rastros, vestígios para quem estiver nos arredores, para que os passantes possam trazer olhares às ações contribuindo com as proposições, tocando e/ou sendo tocados sob algum aspecto. Tudo isto sem que se tenha a necessidade de uma resposta fechada, encerrada em si. Logo, as intervenções artísticas no âmbito urbano acolhem o tempo presente, o tempo do aqui e agora, na efemeridade dos acontecimentos realizados e em comunhão com os demais sujeitos.

Logo, o trabalho de intervir artisticamente sobre o ambiente urbano traz em si um hibridismo de linguagens. Esse hibridismo engendra novas prerrogativas diante da ordem, mobilizando os artistas a construírem novos signos durante a suspensão do ritmo cotidiano, que ocorre na feitura dos seus trabalhos. Durante um curto espaço de tempo, os artistas estabelecem uma espécie de parceria com os locais de ação, abarcando-os em suas propostas. As sequências de ações se potencializam quando os artistas estão predispostos a investigar os espaços, tentando ler, recortar possibilidades que perpassam as relações funcionais do cotidiano. Não se deve entender aqui a parceria como uma proposta que garanta uma suposta ação harmônica. Contrariamente a isto, quando se fala em parceria o que deve ficar explícito é a capacidade dos artistas de abraçarem os espaços da cidade mesmo em conflito com os mesmos, pois as construções autônomas que garantem a democracia nascem da possibilidade do embate. Grandes mudanças estruturais de uma cidade nascem do conflito, de disputas, de ações contrárias ao status quo. Dificilmente as transformações de uma sociedade ocorrem de maneira harmônica. 
Normalmente, as conquistas de novos paradigmas advêm de longos processos de embate, de concorrência entre ideias distintas. No contexto urbano, os artistas que intervêm sobre o fluxo cotidiano trazem pequenas possibilidades de vida frente ao planejamento urbano, fundindo a arte contemporânea e a cidade, na profusão de novos signos que se apresentam initerruptamente ao longo do processo. Dentre as diferentes intervenções artísticas realizadas em espaços públicos, há ações que intervêm em lugares espetacularizados, locais de trânsito intenso de mercadoria, de pessoas, de veículos motorizados, dando passagem à concretude das experiências simbólicas, valorizando outras maneiras de habitar as cidades.

\section{Considerações finais}

A tentativa de padronização dos corpos nas cidades e sua consequente contenção de impulsos que sejam alheios à sociedade de consumo, visa transformar os espaços de convívio em lugares pasteurizados. Na medida em que mais corpos saem deste regime de controle, maior a sistematização da violência institucionalizada a fim de remodelar os comportamentos humanos. Tais enquadramentos buscam alterar a identidade dos sujeitos, bem como suas relações com as comunidades em que vivem, alterando as perspectivas locais e globais de se ver o mundo (GIDDENS, 1995). No entanto, os processos civilizatórios de diluição das subjetividades em prol de uma tendência de massificação favorecem, sem desejar, diferentes embates em proporções variáveis, gerando comportamentos polarizados, na luta de sujeitos ou grupo de sujeitos por direitos iguais e por maiores acessos. Tais sujeitos e/ou grupos buscam alterar os olhares sobre as cidades a partir da assimilação de outros modos de vida, na adoção de outras práticas de uso dos espaços, de compartilhamento de ideias, cujos resultados podem ser experiências estéticas e reflexivas sobre o entorno das cidades. 


\section{Referências bibliográficas}

BAUMAN, Zigmunt. Tempos Líquidos. Tradução de Carlos Alberto Medeiros. Rio de Janeiro: Zahar, 2007. 119p.

BECK, Ulrich. A reinvenção da política: rumo à teoria da modernidade reflexiva. In: BECK, Ulrich; GIDDENS, Anthony; LASH, Scott (Orgs.). Modernização reflexiva: política, tradição e estética na ordem social moderna. Tradução de Magda Lopes. São Paulo: UNESP, 1995. p. 73-133. (Coleção Biblioteca Básica).

CARREIRA, André. Teatro de rua: Brasil e Argentina nos anos 1980: Uma paixão no asfalto. São Paulo: Aderaldo \& Rothschild; HUCITEC, 2007. 216p.

GARROCHO, Luiz Carlos de Almeida. Lugar e convívio como prática espacial e tessitura cênica: as performances urbanas do Coletivo Contraponto (MG). 2015. 299f. Tese (Doutorado em Artes) - Escola de Belas Artes, Universidade Federal de Minas Gerais, Belo Horizonte, 2015.

GASPERI, Marcelo Eduardo Rocco; MUNIZ, Mariana Lima. O espectador transeunte na sociedade do espetáculo: uma análise de "Baby Dolls" Agrupamento Obscena. Performatus, ano 4, n.15, 2016. Disponível em: <http://performatus.net/baby-dolls/>. Acesso em: 24 de abril de 2020. GIDDENS, Anthony. A vida em uma sociedade pós-tradicional. In: BECK, Ulrich; GIDDENS, Anthony; LASH, Scott (Orgs.). Modernização reflexiva: política, tradição e estética na ordem social moderna. Tradução de Magda Lopes. São Paulo: UNESP, 1995. p. 73-133. (Coleção Biblioteca Básica). LEITE, Rogerio Proença. Contra-usos da cidade: lugares e espaço público na experiência urbana contemporânea. 2. ed. Aracaju: UFS; Campinas: Unicamp, 2007. 376p.

MESQUITA, André Luiz. Insurgências poéticas: arte ativista e ação coletiva. 2008. 428f. Dissertação (Mestrado em História Social) - Faculdade de Filosofia, Letras e Ciências Humanas, Universidade de São Paulo, São Paulo, 2008. Disponível em: http://www.teses.usp.br/teses/disponiveis/8/8138/tde-03122008-163436/pt-br.php. Acesso em: 28 de abril de 2020. 